\title{
Penggunaan Bluetooth Android Berbasis Arduino Uno Dalam Mengendalikan Lampu Rumah
}

\author{
*Toni Sukendar'), Ahmad Ishaq ${ }^{2)}$,Mohammad Ikhsan Saputro ${ }^{3)}$ \\ ${ }^{1}$ Teknologi Komputer, Fakultas Teknik dan Informatika, Universitas Bina Sarana Informatika \\ ${ }^{2}$ Sistem Informasi, Fakultas Teknik dan Informatika, Universitas Bina Sarana Informatika \\ ${ }^{3}$ Teknik Informatika, Fakultas Komputer, Universitas Mohammad Husni Thamrin \\ Coresponden author : Toni Sukendar, toni.tns@bsi.ac.id, Jakarta, Indonesia \\ DOI: https://doi.org/10.37012/jtik.v7i1.490
}

\begin{abstract}
Abstrak
Dalam era globalisasi sekarang ini, perkembangan teknologi saat ini sangat bermanfaat bagi kehidupan banyak orang. Semua aspek kehidupan dapat memanfaatkan teknologi sesuai dengan bidang yang dibutuhkan, termasuk kendali rumah. Pada kehidupan manusia sehari-hari tidak pernah lepas dari penerangan lampu listrik. Untuk menyalakan dan mematikan lampu listrik biasanya manusia menggunakan saklar manual. Penggunaan saklar manual dianggap kurang efektif karena memerlukan tenaga manusia untuk mengatur dan memantau lampu pada setiap ruangan. Melihat kurang efektifitas pada saklar manual ini maka dirancang sebuah alat pengontrol lampu rumah menggunakan bluetooth berbasis Arduino uno. Pada perancangan ini menggunakan simulasi miniatur rumah dengan menggunakan android yang di integrasikan dengan bluetooth dan Arduino uno. Perancangan alat ini tersusun menjadi beberapa bagian yang terdiri atas Smartphone Android, modul bloetooth HC- 05, Arduino uno R3, modul relay dan lampu LED. Untuk menyalakan lampu maka smartphone android akan mengirim perintah ke mikrokontroler arduino melalui komunikasi Bluetooth HC-05 untuk menghubungkan modul relay yang berfungsi sebagai switch/saklar sehingga lampu akan menyala sesuai perintah dari smartphone android.
\end{abstract}

Kata kunci : Arduino Uno R3, Smartphone Android, Modul Bluetooth HC-05

\section{Abstract}

In the current era of globalization, current technological developments are very beneficial for the lives of many people. All aspects of life can utilize technology in accordance with the required fields, including home control. In everyday human life it is never separated from the lighting of electric lights. To turn on and turn off electric lights, humans usually use a manual switch. The use of manual switches is considered less effective because it requires human labor to regulate and monitor the lights in each room. Seeing the lack of effectiveness on this manual switch, a home lighting controller designed using an Arduino uno-based Bluetooth. In this design using a miniature home simulation using Android that is integrated with Bluetooth and Arduino Uno. The design of this tool is arranged into several parts consisting of an Android Smartphone, Bluetooth HC-05 module, Arduino uno $R 3$, relay module and LED lights. To turn on the lights, the android smartphone will send commands to the Arduino microcontroller via Bluetooth $\mathrm{HC}-05$ communication to connect the relay module that functions as a switch so that the lights will turn on according to the commands of the android smartphone.

Keywords : Arduino Uno R3, Android Smartphone, Bluetooth HC-05 Module

\section{PENDAHULUAN}

Pengendalian atau control Lampu rumah selama ini menggunakan saklar untuk menghidupkan atau mematikan dan dilakukan secara manual. Saklar sendiri adalah sebagai penghubung atau pemutus aliran listrik yang merupakan adalah komonen atau perangkat 
listrik, karena pengendalian lampu tersebut manual terkadang lupa untuk mematikannya sehingga menyebabkan pemborosan dalam pemakaian listrik, dan hal tersebut banyak kita jumpai di berbagai tempat dan lokasi.

Seiring dengan kemajuan zaman ilmu pengetahuan dan teknologi terutama perangkat elektonika mengalami pekembangan yang sangat pesat dan dirasa bermanfaat bagi kehidupan sehari-hari. Inovasi dan banyak penemuan baru dalam mengembangkan peralatan modern dan lebih canggih selalu terjadi di dalam kehidupan. Peralatan yang menggunakan sistem digital dan otomatis terasa kian diperlukan dalam menghadapi kehidupan di era digital ini.(Heri heryadi, 2017)

Peralatan elektronika adalah salah satu teknologi yang membantu kehidupan manusia menjadi lebih mudah. Salah satu bentuk akses kontrol elektronik yang saat ini banyak dikembangkan adalah sistem kontrol secara jarak jauh, hal ini memungkinkan seseorang dapat mengontrol peralatan elektronik pada jarak jauh, hal ini tentu berguna untuk menunjang kehidupan manusia modern dimana kebutuhan akan mobilitas yang sangat tinggi.(Andrianto, 2015)

Permasalahan yang ada pada saat ini adalah kondisi penerangan sebuah rumah yang masih menggunakan saklar manual sebagai perangkat kontrol penerangan. Hal ini dianggap kurang efektif karena masih menggunakan tenaga manusia untuk mengatur dan memantau sistem pada setiap ruangan. Sehingga sering kali manusia lalai dan merasa malas untuk menghidupkan maupun mematikan lampu pada setiap ruangan.(Maulana \& Purnama, 2017).

Pada penilitian ini akan melakukan prototype alat berbasis Arduino Uno dengan menggunakan Bluetooth Android untuk mengendalikan Lampu yang ada di rumah dengan tanpa menekan saklar dan juga dengan jarak yang agak jauh.

\section{METODE}

Metode penelitian yang digunakan adalah terdiri dari beberapa metode serta tahapannya yang berupa metode pengumpulan data Pustaka atau disebut juga dengan studi literatur, perancangan system, peneraan system dan juga pengujiannya.

\section{Studi pustaka}


Dalam hal ini melakukan pencarian dan penelusuran terhadap berbagai macam Referensi, buku-buku baik melalui perpustakaan atau browsing di dunia internet, atau pun dengan cara lainnya.

Analisa Kebutuhan

\section{A. Hardware}

Tabel 1 .

Kebutuhan Hardware

\begin{tabular}{l|l|l}
\hline No & Hardware & Tipe Keterangan \\
\hline 1 & Arduino Uno & Tipe 3b \\
2 & Modul Bluetooth & HC-05 \\
3 & Modul Relay & 4 channel \\
4 & Led (light Emitting Diode) & - \\
5 & Smartphone & Android \\
\hline
\end{tabular}

\section{B. Software}

Tabel 2.

Kebutuhan Software

\begin{tabular}{l|l|l}
\hline No. & Software & Tipe Keterangan \\
\hline 1 & Arduino IDE & Editor pemerograman Arduino \\
2 & MT APP Invertor & Sistem berbasis Web untuk aplikasi Android \\
\hline
\end{tabular}

\section{Perancangan Sistem}

Yaitu proses penerapan Alat pengendali rumah ini pada Lampu untuk menerangi ruangan dengan Bluetooth.

A. Diagram Blok.

Diagram Blok alat ini sebagai langkah awal desain alur diagram dan menjelaskan proses sistem berjalan dimana setiap bagian memiliki fungsi dan saling terhubung sehingga membentuk suatu sistem pengendali. 


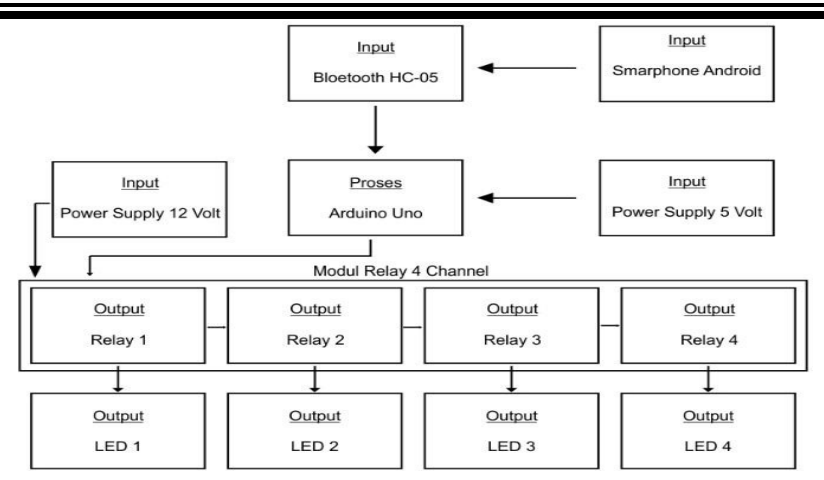

Gambar 1. Diagram Blok

Penjelasan blok diagram alat pengontrol lampu rumah menggunakan bluetooth android berbasis arduino uno sebagai berikut :

1. Input

Komponen input ini merupakan komponen masukan yang akan diproses. Komponen input ini terdiri dari :

a. Power Supply 5 VDC merupakan masukan arus DC 5 volt ke Modul Arduino Uno.

b. Power Supply 12 VDC merupakan masukan arus DC 12 volt ke Modul Relay 4 Channel, dan LED.

c. Smartphone Android berfungsi sebagai pengendali untuk menghidupkan dan mematikan LED.

d. Modul Bluetooth HC-05 berfungsi sebagai penerima data dari smartphone bloetooth android dan mengirimkan data ke Modul Arduino Uno.

\section{Proses}

Proses merupakan komponen utama yang berfungsi sebagai pengelola dan pengendali program data yang diterima dari masukan yang kemudian akan menghasilkan output. Dalam proses ini penulis menggunakan Modul Arduino Uno sebagai pengolah data dan pengendali komponen output elektronik.

\section{Output}

Output merupakan keluaran dari semua proses yang telah dijalankan. Output yang dihasilkan :

a. Modul Relay 4 Channel berfungsi sebagai pengganti saklar penyambung 
dan pemutus arus yang dikendalikan oleh Modul Arduino Uno untuk menghidupkan dan mematikan LED.

b. LED (Light Emitting Diode) berfungsi sebagai lampu penanda berjalannya sistem pengoperasian dan pengganti lampu rumah.

B. Skema Rangkaian

Skema rangkaian alat pengontrol lampu rumah menggunakan bluetooth android berbasis arduino uno sebagai berikut :

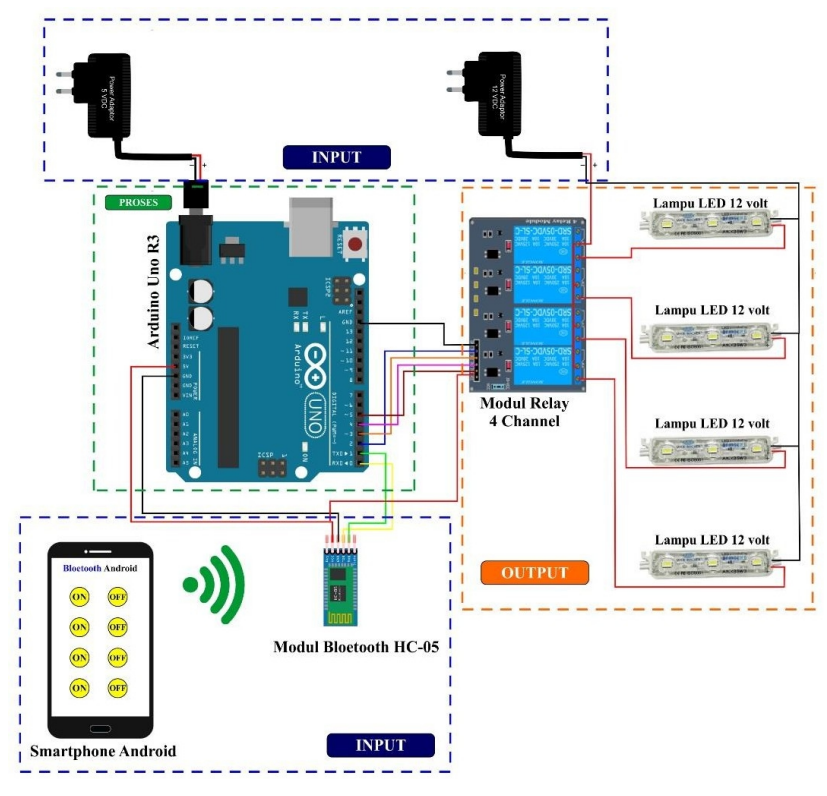

Gambar 2. Skema Rangkaian

Skema rangkaian diatas merupakan rancangan sistem untuk menghidupkan dan mematikan lampu dari jarak jauh menggunakan smartphone android yang sudah terinstal aplikasinya dalam hal ini di beri nama ubsiuno sebagai pengendali berupa tombol ON/OFF, bloetooth hc-05 sebagai penerima data perintah dari smartphone android dan mengirimkan data ke modul arduino uno untuk diolah dan dikendalikan menjadi tindakan output melalui modul relay 4 channel sebagai pengganti saklar untuk menghidupkan dan mematikan lampu.

Agar rancangan sistem ini aktif dan bekerja, hubungkan modul arduino uno dengan adaptor 5 volt dc, kaki negatif lampu led dengan kaki negatif adaptor 12 volt dc, dan kaki positif relay ke kaki positif adaptor 12 volt dc. Jika lampu hidup sesuai dengan 
perintah dari smartphone tandanya alat ini berfungsi, jika lampu mati maka periksa pada power adaptor, modul relay, atau kabel jumper pada rangkaian.

Untuk menjalankan rancangan sistem, pertama hubungkan modul arduino uno dengan adaptor 5 volt dc, kaki negatif lampu led dengan kaki negatif adaptor 12 volt dc, dan kaki positif relay ke kaki positif adaptor 12 volt dc, kemudian sambungkan smartphone android yang sudah terinstal aplikasi ubsiuno dengan modul bloetooth hc-05. Pada modul bluetooth hc-05 disambungkan ke modul arduino uno dimana pin TXD disambungkan pada pin RX, pin RXD disambungkan pada pin TX, pin VCC disambungkan pada pin 5V, dan pin GND disambungkan pada pin GND arduino. Modul arduino akan mengolah data masukan dari modul bluetooth hc-05 yang dikendalikan smartphone android untuk diterjemahkan suatu tindakan melalui modul relay 4 channel yang berfungsi sebagai pengganti saklar untuk menghidupkan dan mematikan lampu led.

Flowchart

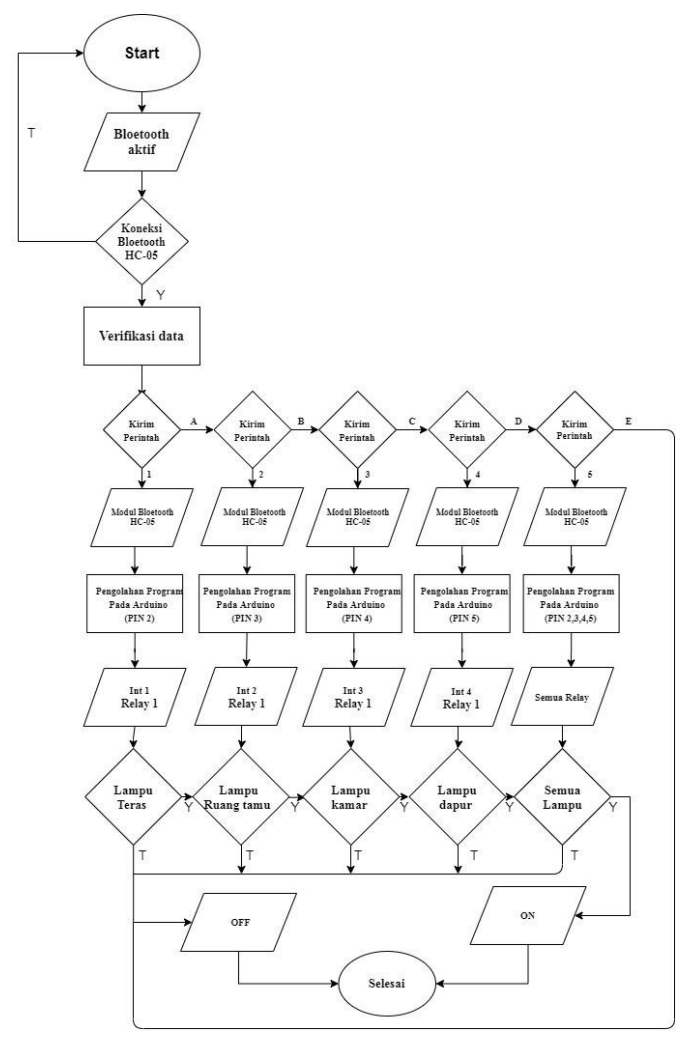

Gambar 3. Flowchart 


\section{Listing Program}

program secara detail pada Arduino IDE dan MIT APP Inventor, meliputi : Inisialisasi program, Pembacaan input, pemrosesan dan pengendalian output program.

\section{Inisialisasi}

\#include $<$ SoftwareSerial.h $>$

SoftwareSerial module_bluetooth $(0,1)$; // pin RX | TX

Listing program untuk mendeklarasikan header file berupa file library yang dibutuhkan untuk memprogram modul bluetooth hc-05 agar dapat melakukan komunikasi dengan modul arduino melalui pin digital input/output 0 yaitu pin RX dan pin 1 yaitu pin TX.

\section{Pembacaan input}

Fungsi void setup() berfungsi untuk menetapkan tipe data yang masuk, baud rate dan komunikasi bluetooth ,pin yang digunakan, dan menetapkan pin pada modul arduino sebagai output.

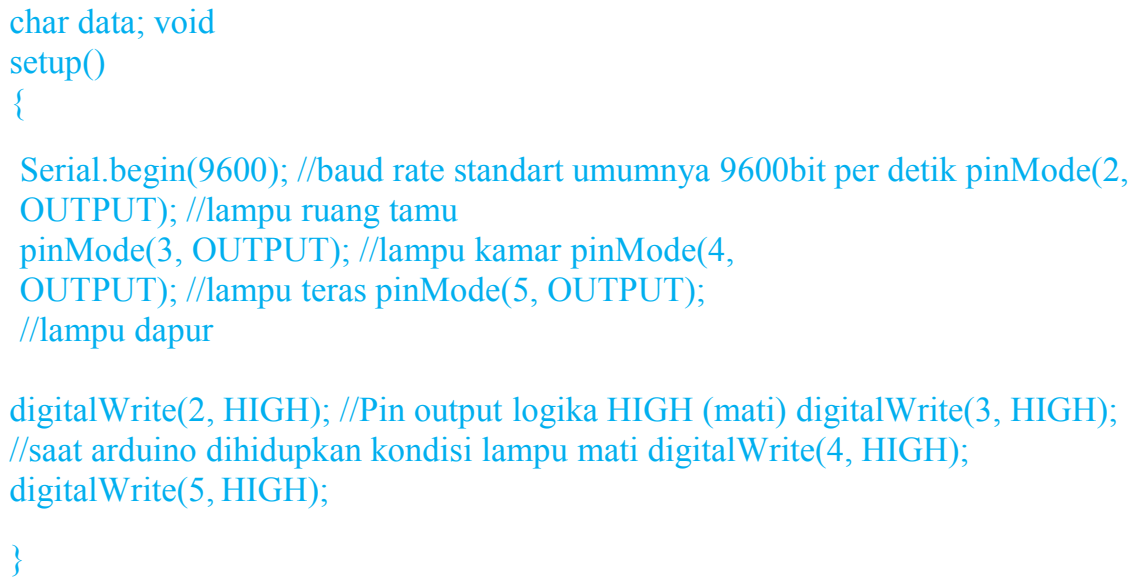

\section{Pemrosesan dan pengendalian output}

Fungsi void loop() berfungsi sebagai program utama untukmengontrol lampu menyala berdasarkan perintah oleh aplikasi UBSI UNO melalui komunikasi bluetooth he-05. void loop ()

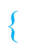


if $($ data $==' 1$ ' $)$

digitalWrite(2,LOW); //bila input (1),maka lampu ruang tamu hidup

\}

else if $\left(\right.$ data $=={ }^{\prime} \mathrm{A}$ ' $)\{$

digitalWrite(2, HIGH); // bila input (A), maka lampu ruang tamu mati

\}

else if $\left(\right.$ data $\left.=={ }^{\prime} 2 '\right)\{$

digitalWrite(3, LOW); //bila input (2), maka lampu kamar hidup

\}

else if $($ data $==$ 'B' $)\{$

digitalWrite(3, HIGH); //bila input (B), makal lampu kamar mati

\}

else if $\left(\right.$ data $=={ }^{\prime} 3$ ' $)\{$

digitalWrite(4, LOW); // bila input (3), maka lampu teras hidup \}

else if $\left(\right.$ data $\left.=={ }^{\prime} \mathrm{C}^{\prime}\right)\{$

digitalWrite(4, HIGH); // bila input (C), maka lampu teras mati

\}

else if $\left(\right.$ data $=={ }^{\prime} 4$ ' $)\{$

digitalWrite(5, LOW); // bila input (4), maka lampu dapur hidup

\}

else if $\left(\right.$ data $\left.=={ }^{\prime} \mathrm{D} '\right)\{$

digitalWrite(5, HIGH); // bila input (D), maka lampu dapur mati

\}

else if $\left(\right.$ data $=={ }^{\prime} 5$ ' $)\{$

digitalWrite(2, LOW);

digitalWrite(3, LOW); // bila input (5), maka semua lampu hidup digitalWrite(4, LOW); digitalWrite(5, LOW);

\}

else if $($ data $==$

'E') \{ digitalWrite(2, HIGH);

digitalWrite(3, HIGH); //bila input (E), maka semua lampu mati digitalWrite(4, HIGH); digitalWrite(5, HIGH);

\}

\} 


\section{HASIL DAN PEMBAHASAN}

Alat pengontrol lampu rumah menggunakan Smartphone Android melalui media Bluetooth merupakan sebuah alat yang dapat memudahkan manusia dalam mengontrol dan mengendalikan lampu dari jarak jauh tanpa harus bersentuhan langsung dengan saklar pada setiap ruangan untuk menghidupkan dan mematikan lampu dengan memanfaatkan Smartphone Android. Dan inilah

hasil design dan rancangan aplikasi

\section{Gambar 4. Tampilan Aplikasi ubsiuno}

tombol ON dan OFF pada gambar diatas adalah berfungsi untuk menghidupkan dan mematikan lampu yang ada pada ruangan.

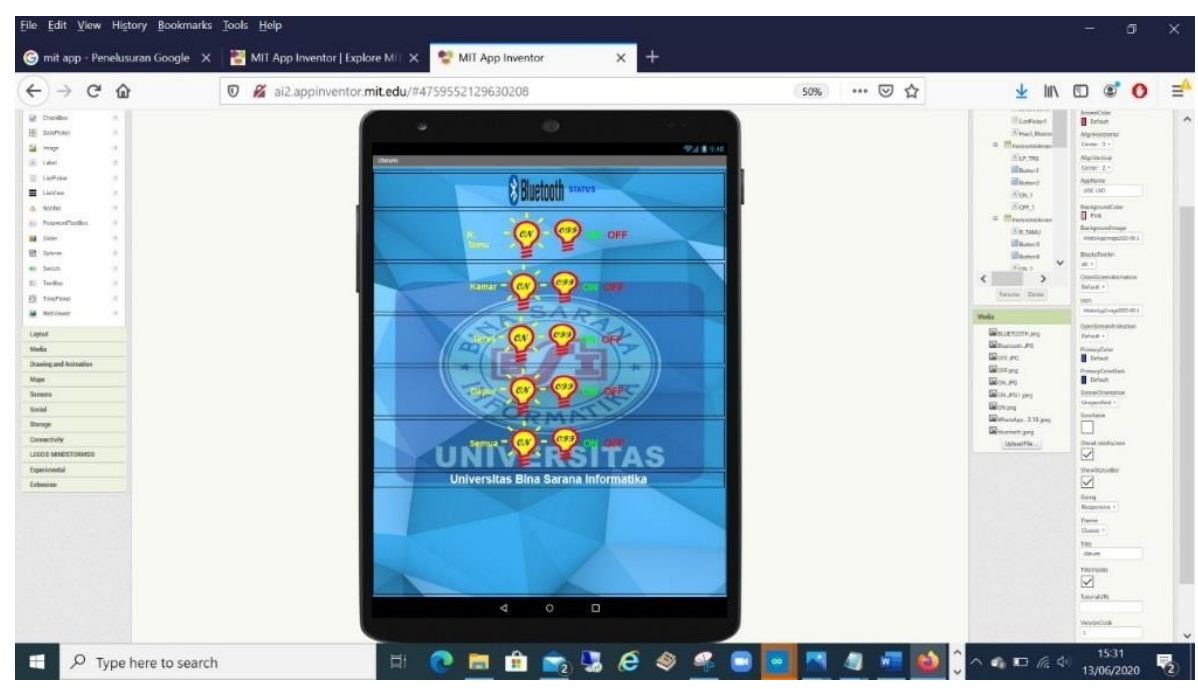

Pengujian

Tabel 3.

Pengujian Koneksi Aplikasi ubsiuno terhadap Bluetooth HC-05

\begin{tabular}{|l|l|l|l|l|}
\hline No & Percobaan & Keterangan & Hasil & Waktu \\
\hline 1 & Bluetooth & $\begin{array}{l}\text { Menghubungkan aplikasi Android } \\
\text { dengan Bluetooth }\end{array}$ & Terhubung & 4 detik \\
\hline 2 & O perintah untuk & $\begin{array}{l}\text { Tombol Lampu } \\
\text { menghidupkan lampu }\end{array}$ & 1 detik \\
\hline
\end{tabular}


Volume 7 No 1: Maret 2021

\begin{tabular}{|l|l|l|l|l|}
\hline \hline 3 & OFF & $\begin{array}{l}\text { Tombol perintah untuk } \\
\text { mematikan lampu }\end{array}$ & $\begin{array}{l}\text { Lampu } \\
\text { mati }\end{array}$ & 1 detik \\
\hline
\end{tabular}

Tabel 4.

Pengujian Jarak Terhubung Aplikasi dan Bluetooth HC-05

\begin{tabular}{|c|c|c|c|}
\hline No & Jarak terhubung & Waktu & Hasil \\
\hline 1 & 2 & 2.30 detik & Terhubung \\
\hline 2 & 4 & 2.88 detik & Terhubung \\
\hline 3 & 6 & 3.36 detik & Terhubung \\
\hline 4 & 8 & 3.65 detik & Terhubung \\
\hline 5 & 10 & 3.95 detik & Terhubung \\
\hline 6 & 11 & - & Tidak terhubung \\
\hline
\end{tabular}

Hasil percobaan yang dilakukan pada bagian output alat, yaitu lampu dapat berjalan sesuai dengan perintah aplikasi ubsiuno berupa tombol ON (lampu hidup) dan OFF (lampu mati) melalui koneksi bloetooth hc-05 dan diproses oleh modul arduino uno . Hasil percobaan ini dijelaskan jarak pengoperasian aplikasi ubsiuno untuk menghidupkan dan mematikan lampu led. Hasil percobaan output dapat dilihat pada tabel 5.

Tabel 5

Pengujian Jarak Pengoperasian Aplikasi ubsiuno

\begin{tabular}{|c|c|c|c|c|}
\hline No & Jarak & Penghalang & Tidak ada Penghalang & Waktu \\
\hline 1 & 1 meter & Hidup & Hidup & 1 detik \\
\hline 2 & 2 meter & Hidup & Hidup & 1 detik \\
\hline 3 & 3 meter & Hidup & Hidup & 1 detik \\
\hline 4 & 4 meter & Hidup & Hidup & 1 detik \\
\hline 5 & 5 meter & Hidup & Hidup & 1 detik \\
\hline 6 & 6 meter & Hidup & Hidup & 1 detik \\
\hline 7 & 7 meter & Hidup & Hidup & 1 detik \\
\hline 8 & 8 meter & Hidup & Hidup & 1 detik \\
\hline 9 & 9 meter & Hidup & Hidup & 2 detik \\
\hline 10 & 10 meter & Mati & Mati & - \\
\hline 11 & 11 meter & Mati & & \\
\hline
\end{tabular}




\section{KESIMPULAN DAN REKOMENDASI}

Berdasarkan hasil percobaan dan pengujian yang telah dilakukan terhadap alat pengontrol lampu rumah menggunakan bluetooth android berbasis arduino uno dapat disimpulkan sebagai berikut :

1. Komponen alat pengontrol lampu rumah ini terdiri dari Arduino UNO, Modul Bluetooth HC-05, Modul Relay 4 Channel, LED (Light Emitting Diode), Smartphone Android, serta perangkat lunak menggunakan Arduino IDE dan MIT APP Inventor.

2. Alat pengontrol lampu berbasis arduino ini dikendalikan dengan aplikasi UBSI UNO yang telah terinstal di dalam smartphone android dan terkoneksi dengan Modul bluetooth hc-05 yang menerima input data berupa perintah dari aplikasi melalui pin RX dan mengirimkan data melalui pin TX untuk diolah dan dikendalikan menjadi output melalui modul relay 4 channel yang berfungsi sebagai pengganti saklar untuk menghidupkan dan mematikan lampu sesuai dengan input perintah dari aplikasi.

Adapun untuk pengembangan kedepannya diantaranya

1. Jarak pengoperasian yang hanya dapat terjangkau dengan 10 meter dengan media bloetooth memungkinkan tidak dapat dijangkau saat pemilik rumah sedang bepergian jauh. Penulis akan mengembangkan dengan jarak yang lebih jauh atau bisa dikendalikan dimanapun dan kapanpun menggunakan aplikasi atau menggunakan SMS dengan modul GSM SIM 800.

2. Pada pengembangan alat kedepan, lampu bisa dikembangkan dengan lampu rumah bertegangan AC 220 volt.

\section{REFERENSI}

Andrianto, A. S. (2015). APLIKASI PENGONTROL JARAK JAUH PADA LAMPU RUMAH BERBASIS ANDROID. APLIKASI PENGONTROL JARAK JAUH PADA LAMPU RUMAH BERBASIS ANDROID, 1-8. https://doi.org/10.1109/BCAA.1996.484974

Dr. Junaidi, S.Si., M. S., \& Prabowo, Y. D. (2018). Project Sistem Kendali Elektronik. 
Efendi, Y. (2018). Rancangan Aplikasi Game Edukasi Berbasis Mobile Menggunakan App Inventor. Rancangan Aplikasi Game Edukasi Berbasis Mobile Menggunakan App Inventor, 2(1), 41.

Kusniyati, H., \& Pangondian Sitanggang, N. S. (2016). Aplikasi Edukasi Budaya Toba Samosir Berbasis Android. Jurnal Teknik Informatika, 9(1), 9-18. https://doi.org/10.15408/jti.v9i1.5573

Maulana, E., \& Purnama, R. A. (2017). Pemanfaatan Layanan SMS Telepon Seluler Berbasis Mikrokontroler Atmega328p Sebagai Sistem Kontrol Lampu Rumah. Jurnal Teknik Komputer Amik BSI, III(1), 93-99.

Mohammad Noviansyah \& Hafdiarsya Saiyar. (2019). PERANCANGAN ALAT KONTROL RELAY LAMPU RUMAH VIA MOBILE. Jurnal AKRAB JUARA, 4(November), 1-11. Retrieved from http://akrabjuara.com/index.php/akrabjuara/article/view/778

Noorman Rinanto, ST. and Syamsiar Kautsar S.ST, 2015. (2018). Modul ajar APAR. Noorman Rinanto, ST. and Syamsiar Kautsar S.ST, 2015, 1-35.

Nuzul Imam Fadlilah \&, \& Arifudin, A. (2018). PEMBUATAN ALAT PENDETEKSI GEMPA MENGGUNAKAN. 6(1), 61-67. Retrieved from https://ejournal.bsi.ac.id/ejurnal/index.php/evolusi/article/view/3582

Rumimper, R., Sompie, S. R. U. A., \& Mamahit, D. J. (2016). Rancang Bangun Alat Pengontrol Lampu Dengan Bluetooth Berbasis Android. 5(3).

Sadewo, A. D. B., Widasari, E. R., \& Muttaqin, A. (2017). Perancangan Pengendali Rumah menggunakan Smartphone Android dengan Konektivitas Bluetooth. Jurnal Pengembangan Teknologi Informasi Dan IImu Komputer, 1(5), 415-425.

Theodorus S Kalengkongan, Dringhuzen J. Mamahit, S. R. U. . S. (2018). Rancang Bangun Alat Deteksi Kebisingan Berbasis Arduino Uno. Jurnal Teknik Elektro Dan Komputer, 7(2), 183-188. https://doi.org/10.35793/jtek.7.2.2018.20169

Zainuri, A., Wibawa, U., \& Maulana, E. (2015). Implementasi Bluetooth HC - 05 untuk Memperbarui Informasi Pada Perangkat Running Text Berbasis Android. 9(2), 163167 